\title{
Comparing ISI and Non-ISI Iranian Medical Research Articles Written in English
}

\author{
Nilofar Bayandor ${ }^{1}$ and Vizayaletchumi Pauline Roslin ${ }^{* 2}$
}

1,2 Faculty of Persian Literature and Foreign Languages, Islamic Azad University, Roudehen, Iran

\section{*Corresponding Author: \\ ×vprosline@yahoo.com}

Received: 15 February, 2021

Accepted: 20 April, 2021

Published: 25 April, 2021

\begin{abstract}
The main aim of this study was to see if any major difference(s) existed between ISI and Non-ISI English medical research articles in their application of major moves. To this effect, 36 randomly selected online articles from each group were subjected to analysis using Fryer's moves analysis framework. These articles were chosen on the basis of ease of accessibility, publication frequency and reputation. To test the hypotheses of this study, a Chi-Square Test of Independence was run to see if there were any significant differences between the number of moves employed in each section of ISI articles with those found in non-ISI articles. Overall, findings revealed that articles in both groups had significantly adhered to the major moves specified in the study's framework. Detail descriptive data analysis showed significant differences between the two groups in the use of Move11 (State the Limitation). It was found that $72 \%$ of the researchers in Type 1 (ISI journals) had described the limitations of their studies while only $36 \%$ of the authors in articles of Type 2(Non-ISI journals) had done so. However, the most striking similarities were seen in Move1 (Present Background Knowledge) and Move 12 (Conclusion). These moves were employed by all the articles in both Types of journals. In addition, two new moves named, Introduce Methods (M3) in the Introduction Section and Sample Selection (M6) in the Method Section were identified during analysis. Though the use of M3 was found to be insignificant, M6 was used by more than half of the articles in both groups. Overall, it was concluded that since articles in both groups had significantly adhered to the major moves specified in the study framework, other underlying criteria besides the application of common moves may exist in choosing articles to be published in Iranian ISI medical journals. These findings contribute to genre research and provide input for further analysis in this context.
\end{abstract}

Keywords: Genre Analysis, Move Analysis, International Scientific Indexing (ISI) / Non-ISI

\section{Introduction}

In the medical field, it is imperative to do research due to the recurring or newly developed ails that afflict man. If the results of studies are reported in ISI journals as compared to Non-ISI ones, this would elevate the value of study results. Also, it could help the researcher gain a good reputation in the international medical community. However, if articles are not accepted due to non-conformity to ISI standards, important information would be missed and efforts on the part of the researcher would be in vain. Since studies have shown that attempts to publish research findings by Iranian medical scholars in ISI journals has been problematic and that research on this context is rare, there is a need to do so to identify the underlying problems/ if any. One way to do so is through moves analysis. 
Over the years, much research has been conducted on scientific research articles either as one entity and/or their sections $[1,2,3,4,5,6,7]$. These research articles are said to be governed by a set of moves. A 'move' is a functional unit in a text used for an identifiable purpose [8]. Also, Swales and Feak [9] defined a "move" as a "bounded communicative act that is designed to achieve one main communicative objective "within the larger communicative objective of the genre "(p.35). According to Bhatia [10], a move has a characteristic specific to a genre which is a concept in the field of linguistics and rhetoric that categorizes writing by similarities in form, style and subject matter. It is believed that knowledge about the function of each move and the structural pattern of the whole text will allow for greater understanding of a specific genre [10], or, in this study, a research article in the field of medicine.

A preliminary review on this context, has revealed that most genre analysis in the field of medicine focused specifically on certain sections of medical research articles. For example, Zho and Wu [11] focused solely on the abstract section of medical research articles while Arsyad [12] based their research on analyzing the discussion section and Mahzari \& Maftoon [13] analyzed the Introduction sections of AmericanEnglish medical research articles. As for comparing the moves of Iranian ISI and non-ISI medical journals in English, Rezaee and Sayfouri [14] analyzed the Introduction and Discussion sections of articles based on the model presented by Nwogu [15]. Thus, there is a need to compare the frequencies of moves normally used in various sections within published articles in Iranian ISI journals with those published in Non-ISI journals. It is believed that by doing so, a general idea of discrepancies/if any, could be revealed. Thus, the main aim of this study is to fill the gaps as revealed in the previous section.

The rationale behind comparing the frequencies of moves used in articles in ISI journals with those from Non-ISI journals is that those in the former have gained more sophistication and academic quality than those in the latter. It is, therefore, expected that comparison of these articles may reveal interesting information to novice writers who may not be familiar with the expectations of this genre within these two journals. It may even reveal the current standard of article writing in both these journals and point to why they were accepted in one and not the other.

\section{Method}

\section{The Coders}

The participants of this study were the coders who analyzed the articles to identify/classify the moves within them. They were experienced researchers in the medical field and currently employed in various hospitals. This is important for this study as the main aim of this study was to analyze medical research articles and choosing experienced participants from this field would provide reliable results.

\section{The Corpus}

The journals chosen in this study were randomly selected journals from online sites. These journals and sites were not only popular among Iranian medical researchers but also familiar to and frequented by the three coders of this study. The articles in these journal followed the standard IMRD (Introduction, Methods, Results, and Discussion) superstructure. This was deemed important as familiarity with these types of articles could help facilitate the coding process.

Thus, the corpus of this study consists of 72 research articles published between January 2015 and November 2016 and from various sub disciplines. These were categorized into two groups Iranian ISI and Iranian Non-ISI, articles. Each group consisted of 36 articles selected respectively from Type A (ISI Iranian journals), Type B (Non-ISI Iranian journals).

\section{Coding Procedure}

In a pilot study, both inter-coder and intra-coder reliabilities were examined to ensure reliability of the results. First, in order to measure the inter-coder reliability, the three raters coded the data for three randomly selected articles. On applying Kappa formula, it was revealed that inter-coder reliability indices $(\mathrm{K}=.84$, .84, and .67) among the three coders were highly desirable and significant. Next, to test intracoder reliability, one coder rated the data twice with an interval of more than two weeks. The Kappa agreement coefficient between the two codings were perfect $(\mathrm{K}=1.00, \mathrm{p}=.000)$. This signified the same coding results of the papers at both times. Therefore, the intra-coder reliability was also assured.

Subsequent to the pilot study, a move classification list was prepared in order provide a reference framework for the coders to aid in identifying the main moves employed in the content of both types of the articles. This list was based on the 10 move categories discussed in Fryer's Model [16]. It should be mentioned here that subsequent to the preliminary analysis of articles, the coders encountered existing moves that did not correspond to the moves listed in Fryer's model and decided to include these two in the move classification list. Thus, the final list contained 12 moves under the IMRD superstructure. This provided the answer to research question 5 of this study. The coders allocated the number 1 to each move that was present and 0 for its non-existence. Table 1 shows the final list used to analyze the moves in both types of articles. 
Table 1

IMRD Sections and corresponding moves applied in this study

\begin{tabular}{|c|c|c|c|c|}
\hline $\begin{array}{l}\text { Section One: } \\
\text { Introduction } \\
\text { (I) }\end{array}$ & $\begin{array}{l}\text { Move One (M1) : } \\
\text { Presentation of } \\
\text { study background }\end{array}$ & $\begin{array}{l}\text { Move two (M2): } \\
\text { Identification of gap(s) } \\
\text { in existing research }\end{array}$ & $\begin{array}{l}\text { Move Three (M3): } \\
\text { Brief Introduction of } \\
\text { Experimental Method }\end{array}$ & $\begin{array}{l}\text { Move Four (M4): } \\
\text { Statement of } \\
\text { research purpose }\end{array}$ \\
\hline $\begin{array}{l}\text { Section Two: } \\
\text { Methods(M) }\end{array}$ & $\begin{array}{l}\text { Move Five(M5): } \\
\text { Description of } \\
\text { material/participants }\end{array}$ & $\begin{array}{l}\text { Move Six (M6): } \\
\text { Justification of sample } \\
\text { selection }\end{array}$ & $\begin{array}{l}\text { Move Seven (M7): } \\
\text { Description of } \\
\text { experimental procedure }\end{array}$ & $\begin{array}{l}\text { Move Eight (M8): } \\
\text { Description of data- } \\
\text { analysis procedure }\end{array}$ \\
\hline $\begin{array}{l}\text { Section Three: } \\
\text { Results(R) }\end{array}$ & $\begin{array}{l}\text { Move Nine (M9): } \\
\text { Report of } \\
\text { observations }\end{array}$ & & & \\
\hline $\begin{array}{l}\text { Section Four: } \\
\text { Discussion (D) }\end{array}$ & $\begin{array}{l}\text { Move Ten (M10): } \\
\text { Discussion of main } \\
\text { findings }\end{array}$ & $\begin{array}{l}\text { Move Eleven (M11): } \\
\text { Study limitations }\end{array}$ & $\begin{array}{l}\text { Move Twelve (M12): } \\
\text { Conclusion }\end{array}$ & \\
\hline
\end{tabular}

\section{Results}

Prior to analysis to test the null hypotheses of this study, descriptive analysis in the form of cross tabulation was first done to seek the numbers of move occurrences in each section of the two types of journals. To test the research hypotheses of the study to seek if there were any significant differences, the number of moves identified in articles of Type I journals were compared with those in Type II journals using series of Chi-Square Tests of Independence.

The first Research Hypothesis sought if any significant differences existed between the frequencies of Moves employed in the Introduction section of ISI and those in the Non-ISI Iranian medical research articles. Table 2 shows the cross-tabulation of the numbers of move occurrences in the introduction section of the two types of journals.

Table 2

Cross-Tabulation: Moves in Introduction Section of Journals Type I and II

\begin{tabular}{llccc}
\hline & & Journal Type & \\
\cline { 3 - 4 } & & $\mathbf{1}$ & $\mathbf{2}$ & Total \\
\hline \multirow{2}{*}{ Moves } & 1Present Background Knowledge & 36 & 36 & 72 \\
& 2Past Research and Missing Info & 31 & 25 & 56 \\
& 3Introduce Methods & 2 & 4 & 6 \\
& 4Research Purpose & 35 & 29 & 64 \\
\hline Total & & 104 & 94 & 198 \\
\hline
\end{tabular}

a. Section $=$ Introduction

As it is evident from Table 2, type II journals have relatively lower evidences of moves in presenting past research and pointing out missing information (M2) as well as in identifying research purposes (M4). However,
M1 (present background knowledge) move was equally high in articles from both journals. In order to see if these differences were significant, a Chi-Square Test of Independence was run (Table 3).

Table 3

Chi-Square Test of Independence: Introduction Section

\begin{tabular}{lccc}
\hline & Value & Df & Asymptotic Significance (2-sided) \\
\hline Pearson Chi-Square & $1.370^{\mathrm{a}}$ & 3 & .712 \\
Likelihood Ratio & 1.382 & 3 & .710 \\
Linear-by-Linear Association & .150 & 1 & .699 \\
N of Valid Cases & 198 & & \\
\hline
\end{tabular}

a. 2 cells $(25.0 \%)$ have expected count less than 5 . The minimum expected count is 2.85 .

As it is evident from Table 3 , the differences between the moves in the Introduction section was not significant $\left(\mathrm{X}^{2}=1.37, \mathrm{p}=.721>.05\right)$. The results showed that there was no overall significant difference between the frequencies of moves employed when comparing ISI and Non-ISI articles and so the first null hypothesis was maintained. But there were individual differences. The frequency table gives details of these 
differences. As you can see, move one, which is presenting the Background Knowledge.was employed by all the authors of articles studied in both groups. Move two, Past Research and Missing Info was seen in $86 \%$ of ISI articles and in $69 \%$ of Non-ISI ones. Move three, Introduce Methods or a Brief description of the Research Method) is identified in this study which is not present in Fryer's Model. Though it had a low frequency of $5.5 \%$ in the first group and a frequency of $11 \%$ in the second group, it did exist in the articles that were analyzed. This move is less visible in medical research articles. The frequency of Move four which is the Research Purpose, in the first group is $94 \%$ and in the second group is $80 \%$. It shows that this move and move one are more important than other moves in Section One of medical research papers.

The second research hypothesis sought if any significant differences existed between the frequencies of Moves employed in the Method section of ISI and those in the Non-ISI Iranian medical research articles. Table 4 shows the cross-tabulation of the numbers of move occurrences in the Method section of the two types of journals.

Table 4

Cross-Tabulation: Moves in Method Section of Journals Type I and II

\begin{tabular}{|c|c|c|c|c|}
\hline & \multicolumn{2}{|c|}{ Journal Type } & \multirow[b]{2}{*}{ Tota } \\
\hline & & 1 & 2 & \\
\hline \multirow[t]{4}{*}{ Moves } & 5Materials & 34 & 33 & 67 \\
\hline & 6Sample Selection & 25 & 20 & 45 \\
\hline & 7Procedures & 34 & 34 & 68 \\
\hline & 8Present the Analyses & 33 & 31 & 64 \\
\hline Total & & 126 & 118 & 244 \\
\hline
\end{tabular}

a. Section $=$ Method

As it is evident from Table 4, type II journals have slightly lower evidences of moves in describing the study materials, providing inclusion criteria, and presenting analysis of the experiment. However, both types of journals showed equally high evidences of describing the procedures. In order to see if these differences were significant, a Chi-Square Test of Independence was run (Table 5).

Table 5

Chi-Square Test of Independence: Method Section

\begin{tabular}{lccc}
\hline & Value & df & Asymptotic Significance (2-sided) \\
\hline Pearson Chi-Square & $.371^{\mathrm{a}}$ & 3 & .946 \\
Likelihood Ratio & .372 & 3 & .946 \\
Linear-by-Linear Association & .005 & 1 & .946 \\
N of Valid Cases & 244 & & \\
\hline a. 0 cells $\left(0.0^{\circ} \%\right)$ have expected count less than 5. The minimum expected count is 21.76.
\end{tabular}

As it is evident from Table 5, the difference between the moves in introduction section was not significant $\left(\mathrm{X}^{2}=.37, \mathrm{p}=.946>.05\right)$.

These results also showed that there was no overall significant difference between the frequencies of moves employed when comparing ISI and Non-ISI articles and so the second null hypothesis was also maintained. Again there were individual differences. The table shows these differences. The frequency of Move five which is Description of material/participants is significant in both types of articles. Around $94 \%$ of articles in the first group and $91 \%$ in the second group applied this move. Move Six-Justification of sample selection has not been mentioned as an independent move in previous studies. However, in this study, it was found that $69 \%$ of articles in the first group and 55\% in the second group had used this move. So it can be a significant result of this study. Move sevenDescription of experimental procedure was seen in $94 \%$ of both ISI articles and Non-ISI ones. The frequency of Move eight- Present the Analyses in the first group was $91 \%$ and in the second group, $86 \%$. So we found that all moves in fryers model was significantly used by both groups.

The third research hypothesis sought if any significant differences existed between the frequencies of Moves employed in the Results section of ISI and those in the Non-ISI Iranian medical research articles. Table 6 shows the cross-tabulation of the numbers of move occurrences in the Results section of the two types of journals. 
Table 6

Cross-Tabulation: Moves in Results Section of Journals Type I and II

\begin{tabular}{lcccc}
\hline & \multicolumn{3}{c}{ Journal Type } & \\
\cline { 2 - 3 } & & $\mathbf{1}$ & $\mathbf{2}$ & Total \\
\hline Moves & 9Findings & 33 & 33 & 66 \\
Total & 33 & 33 & 66 \\
\hline
\end{tabular}

a. Section $=$ Results

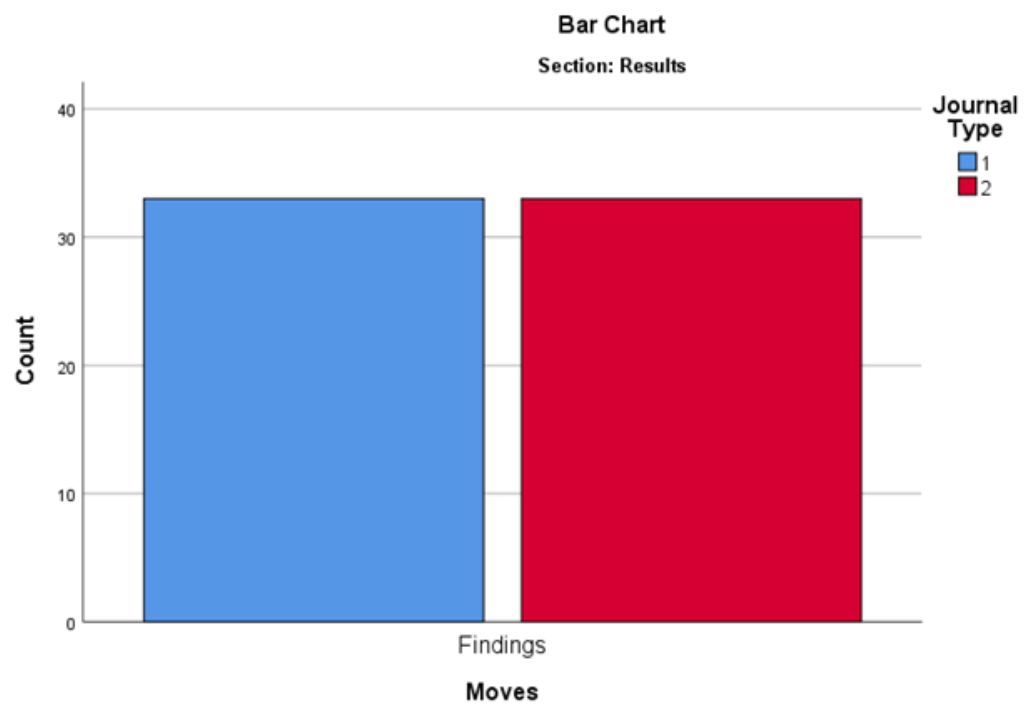

Figure 1. Bar-chart of moves used in results section of ISI and non-ISI journals

As it is evident from Table 6, and Figure 1, the only move of result section, i.e., reporting data/findings, was equally high for both type I and type II journals. In other words, no difference was found in this section.

These results showed that there was no overall significant difference between the frequencies of moves employed when comparing ISI and Non-ISI articles and so the third null hypothesis was also maintained. As can be seen, the frequency table shows that Move Nine is about Findings -This is the only move in the
Results Section. The frequency of $91 \%$ in both groups shows that researchers of these articles see this move as imperative.

The fourth research hypothesis sought if any significant differences existed between the frequencies of Moves employed in the Discussion section of ISI and those in the Non-ISI Iranian medical research articles. Table 7 shows the cross-tabulation of the numbers of move occurrences in the Discussion section of the two types of journals.

Table 7

Cross-Tabulation: Moves in Discussion Section of Journals Type I and II

\begin{tabular}{llccc}
\hline & & \multicolumn{2}{c}{ Journal Type } & \\
\cline { 3 - 4 } & & $\mathbf{1}$ & $\mathbf{2}$ & Total \\
\hline \multirow{3}{*}{ Moves } & 10Discuss Data & 33 & 34 & 67 \\
& 11Limitations & 26 & 13 & 39 \\
& 12Conclusion & 36 & 36 & 72 \\
\hline Total & & 95 & 83 & 178 \\
\hline
\end{tabular}

a. Section $=$ Discussion

Table 8

Chi-Square Test of Independence: Discussion Section

\begin{tabular}{lccc}
\hline & Value & df & Asymptotic Significance (2-sided) \\
\hline Pearson Chi-Square & $3.555^{\mathrm{a}}$ & 2 & .169 \\
Likelihood Ratio & 3.623 & 2 & .163 \\
Linear-by-Linear Association & .003 & 1 & .955 \\
N of Valid Cases & 178 & & \\
\hline
\end{tabular}

a. 0 cells $(0.0 \%)$ have expected count less than 5 . The minimum expected count is 18.19 . 
As it is evident from both Table 7, type II journals have lower evidences of moves in stating the limitation while both journals had almost equally high proportion of discussing the data and equally high proportion of providing conclusion. In order to see if the differences were significant, a Chi-Square Test of Independence was run (Table 8).

As it is evident from Table 8, the difference between the moves in discussion section was not significant (X2 $=3.55, \mathrm{p}=.169>.05)$.

These results also showed that there was no overall significant difference between the frequencies of moves employed when comparing ISI and Non-ISI articles and so the fourth null hypothesis was also maintained. Again, the results of the frequency table are important. As it can be seen, the frequency of move ten which is Discuss data in the first group is $94 \%$ and in the second group is $91 \%$. While move eleven is Limitations. The frequency of this move in both groups was seen to be the lowest when compared to the frequencies of the other moves (besides Move 3) and thus less visible in medical research articles. This study found the frequency of this move in the first group is $26 \%$ and is double the frequency in the second group which is $13 \%$. However, the 100 percent use of Move twelve which is Conclusion, is the same in both groups. This comparative significance of this move, is the same as Move 1 (Present Background Knowledge). So these two moves were the most used among all the other moves. It should not be left unmentioned that, although the significant difference was not found in the data, considering the $\mathrm{p}$ value was relatively close to the cut-point, the results of this section should be interpreted cautiously as not having a significant difference does not mean insignificant difference.

The fifth research question sought if any other moves, besides the ones in Fryer's Model [16], are employed in ISI and Non-ISI Iranian medical research articles. To answer this question, descriptive statistics were run to seek frequency of counts of each move identified by the coders. Two new moves were identified in both the ISI and Non-ISI journals under study.

Table 9

Frequency Counts of Moves in Journals Types I

\begin{tabular}{llcc}
\hline & & $\mathbf{N}$ & Frequency \\
\hline Introduction & Background & 36 & 100 \\
& Past Research and Missing Info & 31 & 86.111 \\
& Introduce Methods & 2 & 5.5556 \\
& Research Purpose & 35 & 97.222 \\
\hline Method & Materials & 34 & 94.444 \\
& Sample Selection & 25 & 69.444 \\
& Procedures & 34 & 94.444 \\
& Present the Analyses & 33 & 91.667 \\
\hline Results & Findings & 33 & 91.667 \\
\hline Discussion & Discuss Data & 33 & 91.667 \\
& Limitations & 26 & 72.222 \\
& Conclusion & 36 & 100 \\
\hline
\end{tabular}

Table 10

Frequency Counts of Moves in Journals Types II

\begin{tabular}{llcc}
\hline Introduction & Background & N & Frequency \\
& Past Research and Missing Info & 36 & 100 \\
& Introduce Methods & 45 & 69.444 \\
& Research Purpose & 29 & 11.111 \\
Method & Materials & 33 & 90.556 \\
& Sample Selection & 20 & 55.657 \\
& Procedures & 34 & 94.444 \\
& Present the Analyses & 31 & 86.111 \\
\hline Results & Findings & 33 & 91.667 \\
\hline Discussion & Discuss Data & 34 & 94.444 \\
& Limitations & 13 & 36.111 \\
& Conclusion & 36 & 100 \\
\hline
\end{tabular}


However, to see whether the use of these moves were significant or not, the frequency Tables (9) and (10) are referred to. It can be seen that the frequency of employing M3 is not high in both journals. To be exact only $2 / 36$ articles in Type 1 (ISI Journals) were identified while $4 / 36$ were seen in Type 2 (Non-ISI journals). As for M6, a comparative significant use of this move is recorded in both journals. In the Type 1 journals, 25/36 (69\%) of the articles analyzed employed this move and 20/36(55\%) articles had this move in the Type 2 journals.

\section{Discussion and Conclusion}

The findings of this study indicated that the most striking difference between them lay in Move11 (State the Limitation). To be exact, out of the 36 articles in Type 1 (ISI journals), 26 (72\%) had described the limitations of their studies while only $13 \%(13 / 36)$ of the authors in articles of Type 2 (Non-ISI journals) had done so. On the other hand, the most striking similarities was seen in Move 1 (Present Background Knowledge) and Move 12 (Conclusion). All the articles in both Types had descriptions of these two moves demonstrating their significant importance over the other moves. Furthermore, the frequency with which Move 9 was employed in Type 1 articles was the same with that of Type 2 articles. However, not all of them used this move (33/36 in both types).

As for the two moves that were identified by the coders as not part of Fryer's model of Moves analysis used in this study, it was found that though Move 3 (Introduce Method- providing a brief introduction of research method) was rarely seen in the articles, move 6 (Sample Selection-providing reason for selecting particular study samples) was found in more than half of the articles analyzed in both groups $(69 \%$ in ISI and 55\% in NonISI). Next, a detailed comparison of the frequency of moves in both groups is presented next with reference to past studies.

M2- Present Background Knowledge. This move was employed by all the authors of articles studied in both groups. This result mirrors the results of a study done by Sayfouri [17]. In his study, the frequency of this move in both groups was also $100 \%$. Also, this similarity in the frequent use of this move in various medical journals was also seen in a study by Jirapanakorn Trakulkasemsuk \& Keyuravong [18]. However, they compared the moves and steps in the various sections among medical journals (though not specifically between ISI and Non-ISI ones). This result points to the high probability that Iranian authors of medical research articles have understood that presenting the history of the subject in question and its role in attracting the audience and its assurance of the author's information about the subject is important (Springer).
M2- Past Research and Missing Info. This move was seen in $86 \%$ of ISI articles and in $69 \%$ of Non-ISI ones. This result is consistent with the result found in a study by Huang [19]. He analyzed online articles related to neurological pathology from The Lancet Journal which is indexed in MEDLINE/PubMed and Scopus and found that $60 \%$ of the articles studied had employed this move. Also, the results related to this move in ISI articles is in line with the study by Rezaee and Seyfouri [14] who found that more than $80 \%$ of ISI medical Research articles employed this move. However, this result widely differs with the results of this same study on the frequency of M2 use in Non-ISI articles. This study which compared moves and submoves of the Introduction and Discussion Sections of ISI and Non-ISI Medical Research Articles found that more than $96 \%$ of Non-ISI has used this move. The omission may point to its role in the author's ability to publish his/her article in ISI journals.

M3- Introduce Methods (Brief description of Research Method). This move had a low frequency of $5.5 \%$ in the first group and a frequency of $11 \%$ in the second group. Though it is less visible in medical research articles, it was seen to be employed by some researchers when presenting their articles online [19]. Huang, though found that all the MRAs studied had employed this move. This move was concluded to be questionable in terms of its necessity to be included in a research article though the frequency of this move points to it being obligatory. This does not coincide with the results of this study as only a comparative few dealt with this move.

M4- Research Purpose. Since the frequency of this move in the first group is $94 \%$ and in the second group is $80 \%$, it is necessary to provide an explanation in the introduction section regarding the purpose of the research in medical research papers. The frequent use of this move in various medical journals was also seen in a study by Sayfouri [17] and this move in her study was identified in both groups with a frequency of $100 \%$. Also, in Fryer's research [16], this move was identified to be present in all articles.

M5- Description of material/participants. The frequency of this move is significant in both types of articles. Around $94 \%$ of articles in the first group and $91 \%$ in the second group applied this move showing its importance. This contradicts a study by Kanoksilapatham [20] who analyzed all sections of 60 articles but in the field of biochemistry and found this move to be obligatory. Again Fryer's research [16] is referred to as the result found here is similar to the one in his study. This move was identified in all articles as it was felt that this move provides the reader with basic information about the material/ participants in the research.

M6- Justification of sample selection - As previously mentioned, this move has not been mentioned as an 
independent move in previous studies, but given its use in medical papers in this study, it has been mentioned as an independent move. The use of this move may be due to its role in the reason for the selection of study material and its effect on result of the study. The frequency of this move in the first group is $69 \%$ and in the second group is $55 \%$. This move in Fryer's research [16] presented as a step of move 5 (describe study material) and was identified in $88 \%$ of his articles. Also, Huang has identified this move in her study of medical research articles as,' Provide inclusion criteria'- Move 6 and the frequency of its use was recorded as $80 \%$ deemed it obligatory. She explained that in randomized samples, it seems that inclusion criteria are beneficial to include because of the justification that it provides for the experimental procedures and results.

M7- Description of experimental procedure - This move was seen in $94 \%$ of both ISI articles and Non-ISI ones. This result echoes the conclusion of a study by Kanoksilapatham [20] who found this move to be obligatory and Nwogu [15] who identified that this move is 'normally required' in Medical Research articles. It was said that through this move, the author explains how he/she achieved the results of the study. Yet again, the frequency of this move in Fryer's research was $100 \%$.

M8- Present the Analyses - This move is said to present the data obtained in relation of the study's methodology. The frequency of this move is significant in both types of articles. Around 91\% of articles in the first group and $86 \%$ in the second group applied this move showing its importance. In this last move of method section, the statistical methods used to explain results is explained. This move was present in all but one his corpus articles (frequency 94\%) [16].

M9- Findings - This is the only move in the Result Section. The frequency of $91 \%$ in both groups shows that both types of articles take this move seriously. Though the significance of this move is high, this result differs with other similar studies which had 100\% employment of this move in the articles studied [16, 19, 21].

M10- Discuss data - In this move, the author compares the results of the study with the results of previous studies and discusses them. The frequency of this move in the first group is $94 \%$ and in the second group is $91 \%$. This result is consistent with the result found in a study by Sayfouri [17] and Fryer's study which reported a $100 \%$ use of this move [16]. Huang too found 100\% use of this move in his corpus and said that this is an essential move of every research article. She continues saying that in order to use the findings and data in the results section, this move must be included [19].

M11- Limitations - This move is said to provide data for areas within which the study might be improved. It also serves to address possible questions that the reader might have. The analysis shows that the frequency of this move in both groups was seen to be the lowest when compared to the frequencies of the other moves (Besides Move 3) and thus less visible in medical research articles. Yet, the frequency of this move in the first group $(26 \%)$ is double the frequency in the second group $(13 \%)$. This move was identified in Sayfouri's study with the same ratio as this study [17]. However, in Fryer's study this move was observed in $88 \%$ of the study corpus articles [16]. Huang's study [19] showed that $80 \%$ of the corpus comprised this move.

M12- Conclusion - The comparative significance of this move is the same as Move 1 (Present Background Knowledge) with a frequency of $100 \%$ in both study groups. However, it should be stated here the analysis revealed that in most of the articles in ISI Type Iranian Medical Research journals and a few Non-ISI ones, this was not considered under the Discussion section but given a separate section to be dealt with. This move was observed in all the corpus articles of similar studies $[16,19,20,21]$.

Overall, it was concluded that articles in both groups had significantly adhered to the moves specified in the study framework. This implies that other underlying criteria besides the application of common moves may exist in choosing articles to be published in Iranian ISI medical journals. One assumption is that rhetorical strengths may play an important role in articles selection in ISI journals. This idea is referred to in a study by Bahrami and Riazi [22]. They stated that writing the Introduction and the Discussion sections of all research articles, compared with the Methods and the Results sections, call for more personal innovations, creativity, and subjectivity. Another assumption is related to the quality and the quantity of move employment. In this context, Swales [8] emphasized the importance of the degree of proficiency of English language, the knowledge of the field, and, the overall level of comprehensibility besides the rhetorical style. These assumptions point to the need for further research and empirical evidence to either be supported or rejected.

\section{References}

1. Swales JM. Research genres: explorations and applications. Cambridge University Press. 2004.

2. Swales JM, Feak CB. Academic writing for graduate students: Essential tasks and skills (2nd Ed.). Ann Arbor, MI: The University of Michigan Press. 2004.

3. Martin JR, Rose D. Working with discourse. London: Continuum. 2003.

4. Dudley-Evan A. Genre analysis: A key to a theory of ESP? Iberica. 2000; 2: 3-11. http://www.aelfe.org/documents/text2-Dudley.pdf 5. Holmes R. Genre analysis and the social sciences: An investigation of the structure of RAs discussion 
sections in three disciplines. English for Specific Purposes. 1997; 16(4): 321-337.

6. Hopkins A, Dudley-Evans A. A genre-based investigation of the discussion sections in articles and dissertations. English for Specific Purposes. 1998; 7: 113122.

7. Wood AS. An examination of the rhetorical structures of authentic chemistry texts. Appl Linguist. 1982; 3: 121-143.

8. Swales JM. Genre analysis: English in academic and research settings. Cambridge: Cambridge University Press. 1990.

9. Swales JM, Feak CB. English in today's research world: a writing guide. Ann Arbor, MA: University of Michigan Press. 2000.

10. Bhatia VK. Analyzing genre: language use in professional settings. London: Longman. 1993.

11. Zho, Wu T. A genre analysis of medical abstracts by Chinese and English native speakers. J Med Coll PLA. 2013; 28(1): 60-64.

12. Arsyad S. A genre-based analysis on discussion section of research articles in Indonesian written by Indonesian speakers. Communication \& Mass Media Complete. Web. 7 Oct. 2013. Int J Linguist. 2013; 5(4): 50-71.

13. Mahzari A, Maftoon P. A contrastive study of the introduction section of English and Persian medical research articles. Iran J Lang Stud. 2007; 1(3): 201-214.

14. Rezaee A, Sayfouri N. Iranian ISI and non-ISI medical research articles in English: A comparative
ESP/EAP move analysis. J Eng Lang Teach Learn. 2009; 52; 212.

15. Nwogu KN. The medical research paper: structure and functions. English for Specific Purposes. 1997; 16: 119138.

16. Fryer DL. Analysis of the generic discourse features of the English-language medical research article. Funct Lang. 2012; 19(1): 5-37.

17. Sayfouri, N. Iranian ISI and non-ISI medical research articles in English: A comparative ESP/EAP move analysis. J Eng Lang Teach Learn. 2009; 52.

18. JirapanakornKing $\mathrm{M}$, TrakulkasemsukKing $\mathrm{M}$. University of Technology Thonburi. A Move Analysis of English Research Article Introductions in Thai and International Medical Journals. 2014; 17(387).

19. Huang D. Genre analysis of moves in medical research articles produced in David Dadurka's fall 2013 ENC 1102.

20. Kanoksilapatham B. Rhetorical structure of biochemistry research articles. English for Specific Purposes. 2005; 24(3): 269-292.

21. Basturkmen H. A genre-based investigation of discussion sections of research articles in dentistry and disciplinary variation. J Eng Acad Purp. 2012; 11: 134144.

22. Bahrami A, Riazi A. Iranian scholars and scientific publications in English: Attitudes, problems and strategies. Paper presented at the $7^{\text {th }}$ International TELLSI Conference, October 20-22, 2009. Yazd University. 2009.

\section{KURMANJ}

Copyright: (C) 2021 The Author(s); This is an open-access article distributed under the terms of the Creative Commons Attribution License (http://creativecommons.org/licenses/by/4.0), which permits unrestricted use, distribution, and reproduction in any medium, provided the original work is properly cited.

Citation: Bayandor N, Pauline Roslin V. Comparing ISI and Non-ISI Iranian Medical Research Articles Written in English. SJMSHM, 2021; 3(2): 1-9.

https://doi.org/10.47176/sjmshm.3.2.1 